\title{
Emotional Intelligence Predicting Leadership Effectiveness: Mediating Role of Personality Traits
}

\author{
Sarwat Sultan 1 \\ Maria Anwar Khan ${ }^{2}$ \\ Frasat Kanwal $^{3}$
}

\begin{abstract}
In recent past the investigations on connection between leadership and emotional intelligence have become significant and one of the most attentive subject in any organization and management research. However, very few studies have addressed the role of personality traits in the relationship between emotional intelligence and leadership effectiveness. This study therefore, was designed to examine the interceding impact of personality traits between the relationship of emotional intelligence and leadership effectiveness among managers. The study was carried out with a sample of 260 male executive heads and managers of different organizations in Multan. Their age range was between 32 and 60 years. All the participants provided data on three questionnaires; Trait Emotional Intelligence Questionnaire, Ten Item Personality Inventory, and Leadership Effectiveness Scale along with a demographic variable sheet. Results indicated that the emotional intelligence significantly predicted the leadership effectiveness. Emotional intelligence was found significantly correlated with personality traits of emotional stability and extraversion. Results pertaining to personality traits indicated that emotional stability and extraversion personality traits were further positively correlated with effective leadership. Findings suggested that personality traits of emotional stability and extraversion played mediating roles between the relationship of emotional intelligence and leadership effectiveness among heads and managers. The study findings have the implications for the organizations while assigning the task of leadership to the new recruitments by keeping their level of emotional intelligence and personality traits for effective leadership. Limitations and future recommendations are also discussed.
\end{abstract}

Keywords: emotional intelligence, emotional stability, leadership effectiveness, personality dispositions.

\section{INTRODUCTION}

\section{Background of the Study}

A person's ability that allows him/her to utilize knowledge, facilitates abstract thinking, and helps in coping with novel and hard situation is known as intelligence (Gardener, 1993). Intelligence is considered as a general ability of an individual to employ his ideas rationally, to act consistently, and to handle expeditiously with circumstances (Weschler, 1958). In the last decades, the construct of emotional intelligence has found unparalleled interest of researchers (Goleman, 1995). Several training modules to enhance emotional intelligence and various courses have been developed and introduced at all levels. To define what exactly emotional intelligence is, many schools of thought exist. In very common description, emotional intelligence is defined as capability of understanding and regulating emotions of ourselves and others (Goleman, 2001).

\footnotetext{
1- Dr. Sarwat Sultan is Chairperson, Department of Applied Psychology at Institute of Management Sciences

Bahauddin Zakariya University, Multan, sarwatsultan@hotmail.com

2- Maria Anwar Khan is a M.Phil Scholar, Department of Applied Psychology at Institute of Management Science

3- Frasat Kanwal is an Assistant Professor, Department of Applied Psychology at Institute of Management Science

JISR-MSSE

Volume 13

Number 2

July-Dec 2015 
Goleman (2001) has clearly differentiated between emotional intelligence and general or pure intelligence. He elaborated that emotional intelligence is the incorporation of feelings and emotions with thinking, making individual recognize other people`s emotions, while general intelligence is only integrating, organizing, and ordering of ideas and thoughts (Goleman, 2001). Bar-On (1997) offered a mixed model for emotional intelligence because it explained that an individual success in dealing with situational stresses is entirely influenced by his non-cognitive abilities, skills, and competencies. The mixed-model is different from ability-based model in a way that the mixed-model integrates other non-cognitive fabrics that may assist recognizing why some people are more successful than others (Mayer, Salovey, \& Caruso, 2000). Goleman (2001) suggested the mixed-model in relation to execution, incorporating one's skills, capabilities, and personality and utilizing their corresponding influences on employees' performance in the organizations.

Leadership theorists examined successful leaders' characteristics and usually associated their magnetic effectiveness to their quality of recognizing issues (Komives, Lucas, \& McMahaon, 2007). A leader always remains engage in taking important decisions on the basis of his understanding the matter (Drucker, 2004). Latest investigations on leadership now have admitted the role of manager's general knowledge of people relations and interactions (Maslow, 1966). Leadership intelligence can be considered as adapted version of successful intelligence that explains the role of a leader within the situations where a leader has to perform efficiently (Service \& Fekula, 2008). An effective leader integrates his insight utilizing suitable communications, emotions, and body language to express basic goals (Lord \& Shondrick, 2011). Charismatic leaders impact their followers by providing the essential goal-orientation and by emotionally fulfilling personal and social needs of followers (Deluga, 2001; Mumford, Antes, Caughron \& Friedrich, 2008).

Several researches have accounted that positive association exists between emotional intelligence and effective leadership (e.g. Sosik \& Megerian, 1999; Gardner \& Stough, 2002). The widely admiration of emotional intelligence has postulated that leaders with emotional intelligence add significant abilities to the role of leadership that confirm their leadership as effective performance. Goleman, Boyatzis and McKee (2002) also demonstrated the connection between emotional intelligence and leadership. They reported that leaders throughout history performed as emotional supervisor, and they remained the responsible to achieve desirable goals. A leader keeping the strong emotional links to subordinates develop positive attitudes in followers that promote combined activities, create concordance, and give importance to participation (Piedmont, 1999).

A standout amongst the most applied concepts which emotional intelligence has been connected with is that of leadership. The leadership writing has delivered innumerable speculations delineating which attributes form the best leader, nonetheless, ebb and flow scholastic research in the range portrays two different sorts of leaders: transformational and transactional (Mandell \& Pherwani, 2003). The transformational leader invigorates enthusiasm among partners, motivates an alternate point of view toward the work, produces a familiarity with the objectives of the organization, creates others to more elevated amounts of capacity, and spurs others to consider the hobbies of the gathering over their own particular diversions (Mayer \& Salovey, 1997). Thusly, transformational leader is said to be embodied the accompanying four aspects: admired impact, persuasive inspiration, savvy incitement, and individual consideration (Bass \& Avolio, 1994). On the other hand, the transactional leader is one whom rewards (or controls) staff on the premise of performance. They stress work models, assignment finishing, and worker agreeability while depending intensely on authoritative prizes and disciplines to impact representative performance (Bass \& Avolio, 1994).

68 July-Dec $2015 \quad$ Volume $13 \quad$ Number $2 \quad$ JISR-MSSE 
Studies exploring the impacts of transformational and transactional leadership have reported that as compared to transactional leadership, transformational leadership anticipate greater degrees of gratification and effectiveness (Hater \& Bass, 1988), greater team activities (Keller, 1995), and greater quantity of attempts on the contribution of employees (Seltzer \& Bass, 1990). In the field of leadership, investigators have similarly suggested that successful and effectual transformational leaders consistently show healthy contacts and emotional intelligence. These components are thought to be crucial to motivate subordinates and to develop firm interactions. Study analyzing transformational leadership and emotional intelligence has systematically reported significant positive relationship between the two concepts. Mandell and Pherwani (2003) in a research that was conducted on emotional intelligence and transformational leadership with 32 employees in administrative status, examined that degree of emotional intelligence assessed through Bar-On Emotion Quotient Inventory was positively correlated to style of transformational leadership.

The early researcher in the domain of leadership and emotional intelligence is Daniel Goleman, who has composed many books and literature on applying emotional intelligence at work place, such as Working with Emotional Intelligence (1998) and The Emotionally Intelligence Workplace (2001a). Goleman proposes that leaders who possess high emotional intelligence have been found as central to organizational success; leaders ought to have the ability to understand workers' emotions that they feel about their job climate, to get involved in issues when come up, to control their own feelings for the sake of obtaining faith of the subordinates, and to realize the societal and political laws in an organization (Goleman, 2001b). Moreover, a leader should have the ability to effect performance of organization by determining a specific working environment. Goleman postulated six different styles of leadership and also explained how these styles influence the organizational environment. Every style is then described through many emotional intelligence capacities presented in model by Goleman, and a style individually may be influential in an organizational context according to the particular situation at hand.

Significantly additionally disturbing is the way that a significant number of the primal leadership skills distinguished by Goleman et al. (2002) appear to fall outside of intelligence. Straightforwardness or uprightness is a character attribute exhibited through predictable conduct, not a mental capacity as promoters case. In addition, the "everything except for IQ" methodology to emotionally intelligent leadership makes it about difficult to discredit the attestation that $80-90 \%$ of a leaders' success rests upon her or his enthusiastic capacity. In the event that emotional intelligence is everything except for cognitive sagacity, then it appears sensible to expect that emotional intelligence abilities and capacities past IQ help more to a success of leader as compared to intellectual capacity. Fearlessness, trustworthiness, persuasive administration, influence, joint effort, and interpersonal correspondence all seem, by all accounts, to be more paramount to leaders than cognitive capacity alone.

Investigations have mentioned that the very efficient and influential leader incorporate maximum of the six outlined styles consistently, exchanging or replacing one with other one most suitable style based on the leadership positions and affairs. In respect to the researches related to insurance companies, where leaders were expert in all four of the substantial styles of leadership, and at schools, where mangers of schools who utilized four or maximum of the leadership styles, it was found that they practice higher performance among learners than comparison schools. Schools were identified as poorest in their performance where heads use only one or two styles of leadership (Hay/McBer, 2000). 
Literature on personality traits has explained that dispositional characteristics are always significantly affected by genetic dispositions and prevail from early childhood to late adulthood remaining consistent over time. Though personality traits remain static, but it has been observed that between late adolescence and thirty years of age, extraversion, openness, and neuroticism have tendency to be declined, while agreeableness and conscientiousness likely to be increased (McCrae, Costa, Lima, Simoes, Ostendorf, Angleitner, Marui, et. al, 1999). Therefore, a personality theorist commented that although emotional intelligence can be promoted in people through training programs and a change in personality trait may remain difficult. However, as personality traits are so enduring, but modifications can be done in attitude or behavior but it will be superficial and short-term in nature (McCrae, 2000).

Leadership effectiveness may vary in respect to personality dispositions including five dimensions; extraversion (propensity to be social, self-assured, and dynamic), emotional stability (propensity to show emotional adjustment), openness to experience (propensity to be imaginative, adaptive, and unlawful), agreeableness (propensity to be relying, ailment, and handling), conscientiousness (achievement and reliableness). Gough (1990) explained that two prominent dimensions of extroversion; dominance and sociability are positively associated with successful leadership. In a Meta analysis by Bass (1990) a list prepared for the possible correlates of effective leadership clearly mentioned that trait of openness to experience was the closest predictor of leadership effectiveness. Zaccaro, Foti, and Kenny (1991) reported that agreeableness or interpersonal sensitivity was directly linked to leadership outcomes. Goldberg (1990) argued that conscientiousness is a significant predictor of leadership. Hogan, Curphy, and Hogan (1994) suggested that emotional stability was found as essential nutriment for effective leadership.

\section{Study objectives}

Based on the literature review available on the relationships between emotional intelligence, personality traits, and leadership characteristics, this study was plotted to see the mediating role of personality traits in the connection between emotional intelligence and leadership effectiveness. Objectives of the study were 1) To see the predictive relationship of emotional intelligence with leadership effectiveness, 2) To assess the predictive relationship of emotional intelligence with personality traits, 3) To analyze the connection between personality traits and leadership effectiveness, and 4) To measure the effect of personality traits as mediators between the predictive capacity of emotional intelligence with leadership effectiveness.

\section{Hypotheses of the study}

To achieve the study objectives, the following hypotheses were formulated; 1) Emotional intelligence will predict leadership effectiveness. 2) Emotional intelligence will be correlated with personality traits. 3) Personality traits will predict leadership effectiveness. 4) Personality traits will mediate the predictive relationship of emotional intelligence with leadership effectiveness.

\section{Significance of the study}

Successful management in any organization is always a source of increasing productive outcomes of that industry. This study will help in understanding how leaders' emotional intelligence and emotional stability can make them effective leaders in any organization. The study findings will also provide the key advantages to the managers for improving their 
emotional intelligence, sociability, and emotional stability by arranging the workshops and seminars in organizational setups. Policy makers of an institute will definitely keep the significance of emotional intelligence and personality traits while assigning the task to its employees.

Figure-1 Conceptual Models

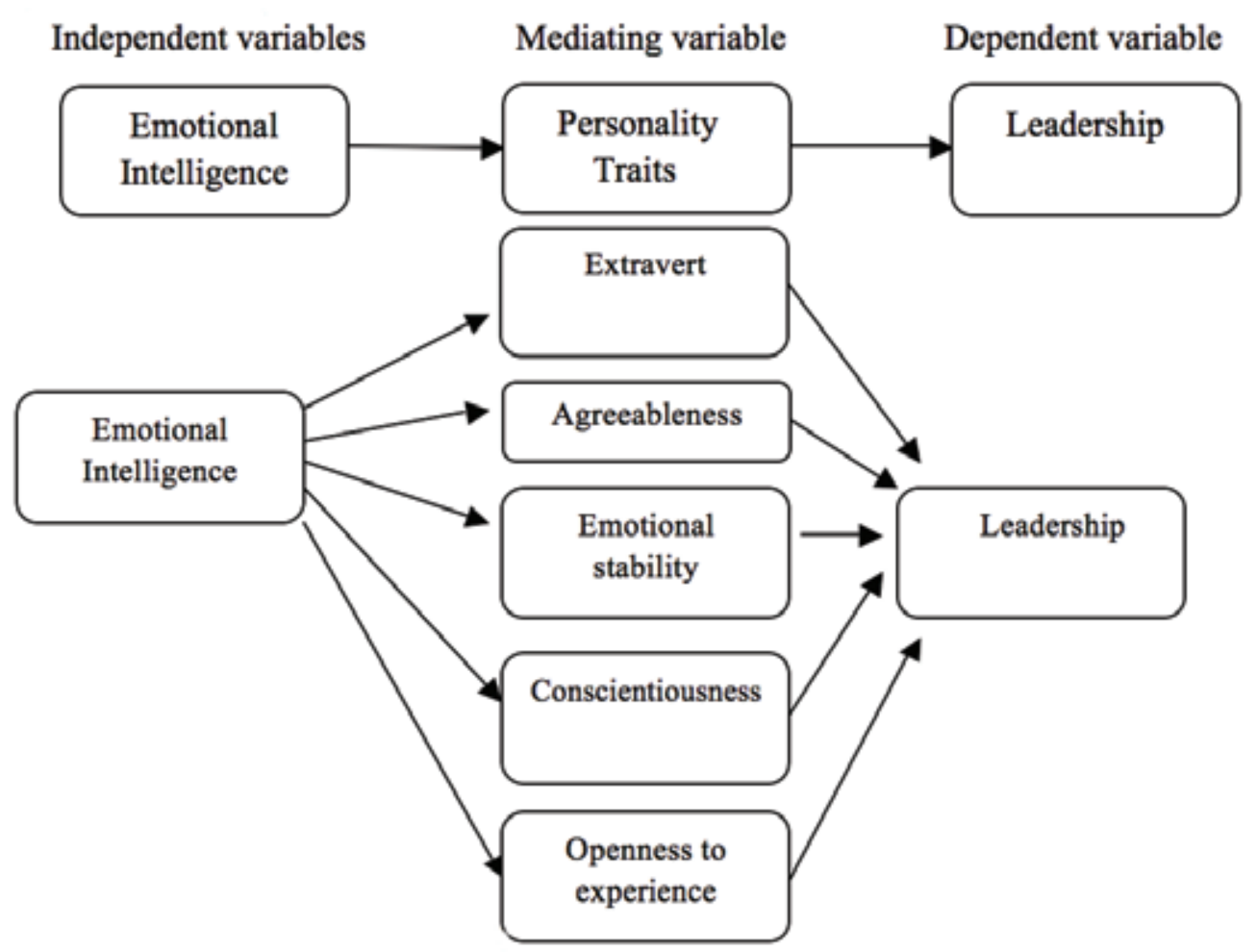

\section{RESEARCH METHODOLOGY}

\section{Research Design}

The research is quantitative in nature and the data were collected through survey research design using three questionnaires along with demographic variables.

\section{Participants}

A sample of 260 male managers aged 32-60 years working in different organizations of Multan participated in the study. Sample was selected through convenient sampling technique. Participants of the study were approached in their working timings of organizations. All the study participants were more or less similar with their education level and cultural background. However, their experience as leader was a varying variable among them. 


\section{Instruments}

Following standardized questionnaires were administered to the participants to obtain the primary data on the study variables;

\section{Trait Emotional Intelligence Questionnaire}

It is a 15-item scale (Petrides \& Furnham, 2006) that asses global trait intelligence of an individual. Responses on this questionnaire are obtained on 7-point Likert Scale that are ratting as $1=$ strongly disagree and $7=$ strongly agree. Emotional intelligence is measured through its 4 subscales: 1) wellbeing, 2) self-control, 3) emotionality, and 4) sociability. Some items are negatively worded in the scale and are first reverse scored before getting the total score. Separate score on each dimension shows the individual level on subscale. The scale was found with a good reliability coefficient of 0.77 .

\section{Ten-Item Personality Inventory}

It is a Ten-item Personality Inventory (Gosling, Rentfrow, William, \& Swwan, 2003) that measures five personality traits; 1) emotional stability, 2) extraversion, 3) agreeableness, 4) openness to experience, and 5) conscientiousness. Participants provide their responses on 7-point Likert scale ranging from strongly disagree (1) to strongly agree (7). Responses on even items are first recoded before obtaining a total score on each of five traits. Scores on all traits separately are calculated by summing the responses on 5 and 10 for openness to experiences, 4 and 9 for emotional stability, 3 and 8 for conscientiousness, 2 and 7 for agreeableness, and 1 and 6 for extraversion. Reliability coefficient of this scale was found 0.62 .

\section{Leadership Effectiveness Scale}

Leadership Effectiveness Scale (Callaghan n.d) comprising 30 items describes 30 patterns of leadership that usually an effective leader commonly utilized in his/her practices. 4-points ratting scale ranging from 1-4 is used for responses wherein 4 shows "Usually if not always, 3 indicates "Fairly often", 2 reveals "Occasionally", and 1 depicts "Rarely if ever". Overall score is computed by adding the responses on all items. Scores are interpreted as; scores from 105 to 120 shows "Strong Leader", scores from 90 to104 indicates "Good Leader", and scores from 75 to 89 "mean needs to improvement". The reliability coefficient of this scale was found .90 .

\section{Procedure}

Organizations' mangers were first contacted by sending them the consent letters wherein the purpose of the study was briefed to them. Initially 300 managers from different organizations were approached in Multan. Of these 300 managers, total 260 managers returned the letters with their willingness to participate in the study. Researchers obtained the appointment from managers to collect the data at their working place. Three questionnaires including ten-item personality traits, cultural intelligence scale, and leadership effectiveness scale were given to them to fill out. All the sufficient instructions about how to fill the questionnaires and guidelines for better understanding of questionnaires were given to them. An assurance for their response confidentiality was also briefed to them and they were told that all the responses given by them will be kept hide from others and only be utilized for the research purpose. Collected information was then analyzed using SPSS-17. 


\section{RESULTS}

To test the hypothesized model of the study, descriptive statistics, Pearson correlations, Linear Regression Analyses, and sobel tests were performed on SPSS-17. To assess the relationships among study variables, Pearson correlation was performed and to check the prediction of independent variables on dependent variables, the path analysis was done through smart-PLS2. Online sobel test was run, to measure the mediation from personality traits for the predictive relationship of emotional intelligence with leadership effectiveness.

Table 1: Mean, SD, \& Correlations Matrix for the Scores on Emotional Intelligence, Leadership Effectiveness, \& Personality Traits

\begin{tabular}{lllllllllll}
\hline & $\mathrm{M}$ & $\mathrm{SD}$ & 1 & 2 & 3 & 4 & 5 & 6 & 7 \\
\hline 1 & Emotional Intelligence & 132. & 19.3 & 1 & & & & & \\
& 7 & & & & & & & \\
2 & Leadership & 77.2 & 15.7 & $.21 * *$ & 1 & & & & \\
& Effectiveness & 5 & & & & & & & \\
3 & Openness to experience & 7.74 & 3.37 & $-.20^{* *}$ & $.20 * *$ & 1 & & & \\
4 & Extroversion & 9.78 & 3.10 & $.45^{* *}$ & $.62^{* *}$ & $-.32 * *$ & 1 & & \\
5 & Conscientiousness & 8.50 & 2.49 & .02 & .05 & $.23 * *$ & -.07 & 1 & \\
6 & Emotional Stability & 9.51 & 2.90 & $.46^{* *}$ & $.29 * *$ & $-.12^{*}$ & $.34 * *$ & -.03 & 1 \\
& & & & & & & & & \\
7 & Agreeableness & 8.96 & 2.74 & $.19 * *$ & .04 & $.22 * *$ & -.09 & -.05 & $.36 * * 1$ \\
\hline
\end{tabular}

$* \mathrm{p}>.05, * * \mathrm{p}>.001$

Results in Table 1 indicates the mean, standard deviations, and correlations coefficients among all three study variables. Findings suggest that emotional intelligence is significantly positively correlated with leadership effectiveness $(\mathrm{r}=.21)$, personality traits of extroversion $(r=.45)$, emotional stability $(r=.46)$, and agreeableness $(r=.19)$, while is significantly negatively correlated with openness to experience $(r=-.20)$. However, no connection has been found between emotional intelligence and conscientiousness. Results further demonstrate that leadership effectiveness is significantly associated with personality traits of extroversion $(\mathrm{r}=$ $.62)$, openness to experience $(r=.20)$, and emotional stability $(r=.29)$.

Table 2: Standardized Coefficients and t-values from Path analysis of the trans-contextual Model

\begin{tabular}{lcc}
\hline Hypothesized Paths & Path Coefficients & t Statistics \\
\hline Emotional intelligence -> Openness to Exp & -0.62 & 2.49 \\
Emotional intelligence -> Extroversion & $1.34^{* *}$ & $8.13^{* *}$ \\
Emotional intelligence -> Conscientiousness & -0.17 & 0.95 \\
Emotional intelligence -> Emotional Stability & $2.20^{* *}$ & $6.31^{* *}$ \\
Emotional intelligence -> Agreeableness & -0.17 & 0.92 \\
Openness to Exp -> Leadership Effectiveness & 0.22 & 1.27 \\
Extroversion -> Leadership Effectiveness & $.121^{*}$ & $1.99^{*}$ \\
Conscientiousness -> Leadership Effectiveness & 0.12 & 0.67 \\
Emotional Stability -> Leadership Effectiveness & $-.226^{*}$ & $2.16^{*}$ \\
Agreeableness -> Leadership Effectiveness & 0.22 & 0.85 \\
\hline
\end{tabular}

$* \mathrm{p}>.05, * * \mathrm{p}>.001$ 
Results in Table 2 present the beta coefficients and t-values for the hypothesized paths. Findings from path analysis entail that emotional intelligence significantly predicts the traits of extroversion $(b=1.34)$ and emotional stability $(b=2.20)$. Results further show that personality traits of extroversion and emotional stability are significantly predicting the leadership effectiveness $(b=1.21, b=-.226$ respectively).

Figure-2 Path Analyses

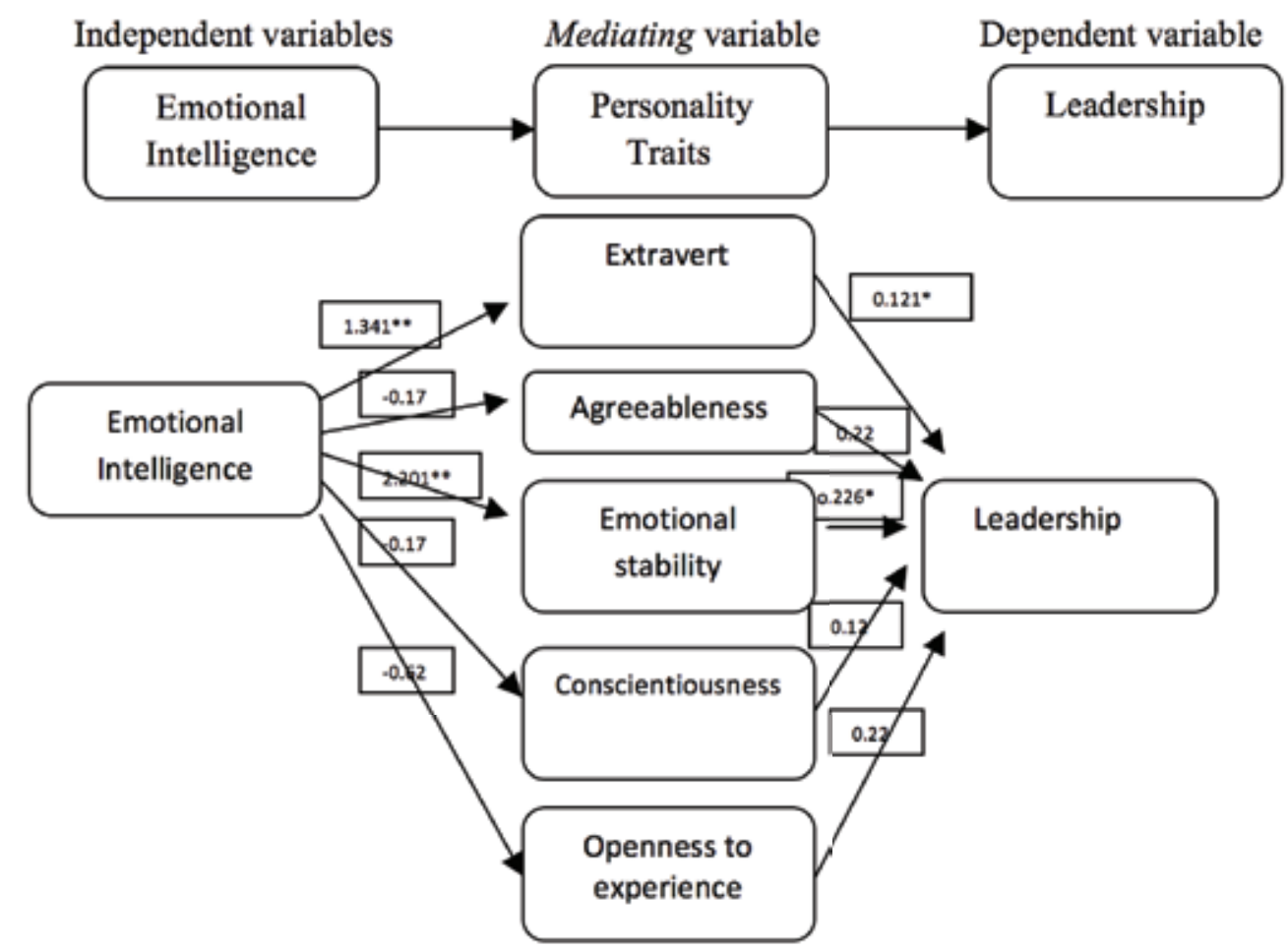

Table 3: Sobel Test Showing Mediation effect of Personality Traits for the relationship between Emotional Intelligence and Leadership Effectiveness

\begin{tabular}{llllccc}
\hline Paths & BA & SEA & BB & SEB & Sobel Test & p \\
\hline EI $\rightarrow$ OPE $\rightarrow$ LE & 0.62 & 0.25 & 0.22 & 0.17 & 1.14 & 0.06 \\
EI $\rightarrow$ EXT $\rightarrow$ LE & 1.341 & .243 & .121 & .040 & 2.65 & $0.00^{*}$ \\
EI $\rightarrow$ CON $\rightarrow$ LE & 0.17 & 0.18 & 0.12 & 0.18 & 0.54 & 0.15 \\
EI $\rightarrow$ EMO $\rightarrow$ LE & 2.201 & .452 & -.226 & .032 & 4.01 & $0.00^{*}$ \\
EI $\rightarrow$ AGR $\rightarrow$ LE & -0.17 & 0.19 & 0.22 & 0.26 & -0.61 & 0.13 \\
\hline
\end{tabular}

$* \mathrm{p}>.001$

Findings in Table 3 indicate the mediation effects of five personality traits between the relationship of emotional intelligence and leadership effectiveness. Findings reveal the significant mediating role of extroversion personality (2.65) and emotional stability trait (4.01) in the association of emotional intelligence and leadership effectiveness. 


\section{DISCUSSION}

In the current study we explored the relationships among employees' emotional intelligence, big five personality traits, and leadership effectiveness. The study basically aimed to understand whether emotional intelligence has any connection to personality traits (emotional stability, extroversion, agreeableness, conscientiousness, and openness to experience) and leadership effectiveness. We found the significant positive relationship between emotional intelligence and leadership effectiveness. These findings entail that when employees who perform and act at their workplace with emotional intelligence, they can prove themselves as efficient leaders. The hypothesis stated in a manner explaining the predictive role of emotional intelligence in effective leadership has been supported in the current study. This finding is consistent with the previous researches that claim for the same connection between emotional intelligence and leadership effectiveness (e.g Bass \& Avolio, 1994).

Mandell and Pherwani (2003) documented that the most practical aspect of emotional intelligence with which it has been connected with is that of leadership. The literature on leadership has presented various theoretical frame works that describe the essential characteristics for effective leader at the most, and discussed the two dimensions of leadership: transformational and transactional (Mandell \& Pherwani, 2003). Bass and Avolio, (1994) explained that the transformational leader produces motivation, inspiration, awareness, and competencies among the employees. And this could be possible if the leader is emotionally intelligent to handle the situations in the organizations.

These calculated and coherent challenges don't imply that leadership researchers and specialists ought to forsake emotional intelligence. Passionate qualities have since a long time ago possessed a focal place in leadership studies and are encountering a restoration in the current writing (e.g., Ashkanasy, Härtel \& Zerbe, 2000: Ashforth \& Humphrey, 1995). Emotions and sentiments assume an essential part in such leadership undertakings as propelling supporters, choice making, creating interpersonal connections and molding society (George, 2000). A few specialists and scientists same see organizations as emotional, not sane coliseums. Some women's activist associations like The Body Shop make the representation and affirmation of feeling a focal quality (Martin, Knopoff \& Beckman, 1996). These different strands bear witness to the critical part feelings play in leadership and organization.

Findings pertaining to another path suggesting the association between emotional intelligence with personality traits revealed that the constructs of emotional intelligence and big five personality traits have associations with each other. We found that emotional intelligence was significantly positively correlated with personality traits of extroversion, emotional stability, and agreeableness, while is significantly negatively correlated with openness to experience. However, no connection was found between emotional intelligence and conscientiousness. These findings proof that if leaders are emotionally intelligent then they are also emotionally stable and can understand not only their own emotions but also of others' emotions. The ability of emotional stability makes leaders more social as well. Leaders with their enhanced capacity of emotional intelligence can have good relations with their subordinates which is ultimately in benefit to the better performance of organization.

The literature on the investigation of emotional intelligence and personality traits has demonstrated that the leader ability to execute, to incorporate competencies, capabilities correspond to personality affect the performance of other workers in the organizations (Goleman, 2001). The current findings are in tune with the study by Hind, Wilson, and Lenssen (2009) who posited that leadership inherited the personal qualities needed to be 
effective leadership. They added that leadership influences the globalization of businesses to ensure sustainability that is possible with the combination of good personality characteristics and emotional intelligence. One more example could be helpful to understand how emotional intelligence is useful in occupational success. Rosenthal and his colleagues at Harvard explored over two decades ago that people who were best at recognizing others' feelings and emotions were more successful in their work as well as in their social lives (Rosenthal, 1977).

Results further demonstrated that personality traits were related to leadership effectiveness. Current study suggested that leadership effectiveness is significantly associated with personality traits of extroversion, openness to experience, and emotional stability. The findings are in accord with the previous literature that produces many findings entailing the positive connection between extroversion and leadership effectiveness. It has been previously affirmed that extrovert personality is considered as vital characteristic for being an influential leadership (e. g. Judge, Bono, Ilies, \& Gerhardt, 2002). They further exerted that effective leadership has been found consistently related with trait of extroversion. They claimed that employees who were more extrovert, were found good leaders in future. The present findings are also supported by the meta analysis by Bono and Judge (2004) who found extrovert personality was the significant predictor of transformational leadership.

Moreover consistent to our findings, Bachman (1988) also explored that the most effective and successful leaders in the United States Navy were affectionate, more tenderer, social, emotionally expressive, striking, and outgoing. Past investigations on emerging leaders proposed that they are competent and experienced in taking in and understanding emotional information. This study demonstrated that emergent group leaders were socially perceptive and uniquely able to identify and understand unstated team needs (Chowdhry \& Newcomb, 1952).

Another important finding of the current study mentioned that emotional stability was related to effective leadership. It can be justified that emotional stability among employees and supervisor influences the leadership qualities. Results are in accordance with the work of Felfe and Schyns (2006) that emotional stability was positively related to their perception of effective leaders. Ferris, Treadway, Perrewe, Brouer, Douglas, \& Lux, (2007) work also provide the strength to the current findings as they stated that emotionally stable leaders fasten and ensure in themselves and competent in their skills and therefore lack the nervousness and show the emotional stability. Emotionally stable leaders may build and manage interactions through effective dialogue, impressive talk, and problem resolution, as well as may make effectual decisions and can supervise through employment (Rockstuhl, $\mathrm{Ng}$, Seiler, Ang, \& Annen, 2009).

An interesting finding of the present was linked to see the mediating role of big five personality traits; extroversion, emotional stability, agreeableness, openness to experience, and conscientiousness between the relationship of emotional intelligence and leadership effectiveness. Findings suggested that personality traits of extroversion and emotional stability mediated the association between emotional intelligence and influential leadership. These findings implied that leaders who were emotionally intelligent, were with extrovert personality, and were emotionally stable proved themselves as influential leaders for their followers in organizations. Results finally confirmed that personality traits of extroversion and emotional stability interceded the relationship of emotional intelligence and leadership effectiveness. 
The study findings overall suggest that a leader should have emotional stability and maturity because this ability can develop the healthy relationships with coworkers and subordinates. A leader should have the social skills and social competency for understanding the people behaviors at work. If a leader is emotionally intelligent and can realize the feelings of own and others, will be an effective leader for that organization. In this way a leader can manage the many problems confronted to organization just by controlling the emotions of others with the help of his emotional consistency and extraversion trait. In short, a leader of emotional intelligence can be more effective if is emotionally stable and extrovert in personality.

\section{Key Findings}

1. Findings from Pearson correlation matrix propose that emotional intelligence is significantly positively related to leadership effectiveness.

2. Emotional intelligence is also found as associated with personality traits of extroversion, emotional stability, and agreeableness.

3. Results further demonstrate that personality traits of extroversion, openness to experience, and emotional stability are further positively linked to leadership effectiveness.

4. Path analysis shows that emotional intelligence significantly predicts the traits of extroversion and emotional stability.

5. Results further shows that beta coefficients of extroversion and emotional stability traits are significantly predicting the leadership effectiveness.

6. Sobel test findings reveal the significant mediating role of extroversion and emotional stability in the association of emotional intelligence and leadership effectiveness.

\section{CONCLUSION}

By conceiving the previous literature and in the light of current study, it does appear reasonable to deduce that emotional intelligence is a consistent predictor of leadership behaviors. Managers who are with high emotional intelligence have effective leadership in their organizations. It was explored that individual differences in personalities in general also affect leadership patterns. However, all dispositional traits are not the significant determinants of leadership effectiveness. In relation to the Big Five personality characteristics, some dimensions as predictors (e.g., extroversion and emotional stability) were found more substantial for efficient leadership as compared to other traits. Study also proposed that agreeableness, openness to experience and, conscientiousness personality dimension from the Five Factor Model were not always enough to anticipate the effective leader. This study has shed light on an interesting finding that extroversion and emotional stability mediated the relationship of emotional intelligence and leadership effectiveness. It does mean that emotional intelligence when is combined with personality traits of extroversion and emotional stability produce the effective leaders.

\section{LIMITATIONS AND SUGGESTIONS}

In spite of that the study has made several interesting findings to understand the role of personality characteristics in emotional intelligence and effective leadership, the study also acknowledge some limitations of it. The sample size and sampling technique are the major threats to the external validity of the findings and the results have no potential to be generalized to the whole population of managers. Sample size is small and sampling technique is convenient that limits the generalizability of the findings. Therefore, the future study should have a larger number in sample through random sampling selection. Further this study has just 
explored the big five personality traits while many other personality dimensions need to be examined in the context of emotional intelligence and leadership effectiveness. For instance, optimism vs. pessimism, Type A/B, and internal vs. external causal attribution should be investigated in respect to leadership effectiveness. On the basis of these findings the behaviors of leaders can be interpreted in the light of their levels of emotional intelligence and type of personality. Therefore, it is recommended that social, emotionally intelligent and stable mangers or executive heads should be employed in the organizations for the occupational success, and workshops and seminars should be arrange to train and educate the employees in enhancing the leadership qualities and emotional intelligence.

\section{REFERENCES}

Ashforth, B., \& Humphrey, R. (1995). Emotion in the workplace: A reappraisal. Human Relations, 48(2), 97-125.

Ashkanasy, N. M., Härtel, C. E. J., \& Zerbe, W. (eds.) (2000). Emotions in the workplace: Research, theory, and practice. Westport, CT: Quorum Books.

Bachman, W. (1988). Nice guys finish first: A SYMLOG analysis of U.S. Naval commands. In R.B. Polley (Ed.) The SYMLOG Practitioner: Applications of Small Group Research. New York: Praeger.

Bar-On, R. (1997). Bar-On Emotional Quotient Inventory (EQ-I): Technical Manual. Toronto, Canada: Multi-Health Systems.

Bass, B. M. (1990). Bass and Stogdills' handbook of leadership. New York; Free Press. Bass, B. M. \& Avolio, B. J. (1994). Improving Organizational Efectiveness Through Transformational Leadership. Thousand Oaks, CA: Sage.

Bono, J. E., \& Judge, T. A. (2004). Personality and transformational and transactional leadership: A meta-analysis. Journal of Applied Psychology, 89(5), 901-910.

Callaghan. A. (n.d). Team building solutions. London: Lymington.

Chowdhry, K. Newcomb, T. M. (1952). The relative abilities of leaders and non-leaders to estimate opinions of their own groups. Journal of Abnormal and Social Psychology, 47, 57-61.

Deluga, R. (2001). American presidential Machiavellianism: Implications for charismatic leadership and rated performance. Leadership Quarterly, 12(3), 339-363.

Drucker, P. F. (2004). What makes an effective executive? Harvard Business Review, 82(6), 58-61.

Felfe, J., \& Schyns, B. (2006). Personality and the perception of transformational leadership: The impact of extraversion, neuroticism, personal need for structure, and occupational self efficacy. Journal of Applied Social Psychology, 36(3), 708-739.

Ferris, G. R., Treadway, D. C., Perrewe, P. L., Brouer, R. L., Douglas, C., \& Lux, S. (2007). Political skill in organizations. Journal of Management, 33(3), 290-320. 
Gardner, H., (1993), Frames of Mind: The Theory of Multiple Intelligences, Basic Books, NY.

Gardner, L. \& Stough, C. (2002), Examining the relationship between leadership and emotional intelligence in senior level managers, Leadership \& Organization Development Journal, 23(2), 68-78.

George, J. M. (2000). Emotions and Leadership: The role of emotional intelligence. Human Relations, 53(8), 1027-1055.

Goldberg, L. R., (1990). An alternative "description of personality": The Big Five factor structure. Journal of Personality and Social Psychology, 59, 1216-1229.

Goleman, D. (1995). Emotional Intelligence: Why it can matter more than IQ.. New York, NY: Bantam Books.

Goleman, D. (1998). What makes a leader? Harvard Business Review, 1, 93-104.

Goleman, D. (1998). Working with emotional intelligence. New York: Bantam Books.

Goleman, D. (2001a). An EI-Based Theory of Performance. In C. Cherniss \& D. Goleman (Eds.), The emotionally intelligent workplace: how to select for, measure, and improve emotional intelligence in Individuals, Groups, and Organizations (pp. 27-44). San Francisco, CA: Jossey-Bass.

Goleman, D. (2001b). Emotional intelligence: Issues in paradigm building. In C. Cherniss and D. Goleman (Ed's.), The Emotionally Intelligence Workplace. San Francisco: Jossey-Bass.

Goleman, D., Boyatzis, R.E., \& McKee, A. (2002). Primal Leadership: Realising the Power of Emotional Intelligence. Boston, MA: Harvard Business School Press.

Gosling, S. D, Rentfrow, P.J, William, B., \& Swwan, J. (2003). A very brief measure of the Big-Five personality domain. Journal of Research in Personality, 37, 504-528.

Gough, H. G., (1990). Testing for Leadership with the California Psychological Inventory. In K. E. Clark and M. B. Clark, (Ed), measure of leadership (pp. 335-379). West Orange, NJ: Leadership Library of America.

Hater, J.J. \& Bass, B.M. (1988). Superior's evaluations and subordinates' perceptions of transformational and transactional leadership. Journal of Applied Psychology, 73 (4), 695-702.

Hind, P., Wilson, A., \& Lenssen, G. (2009). Developing leaders for sustained business. Corporate Governance, 9(1), 7-22. doi: 10.1108/14720700910936029

Hogan, R., Curphy, G. J., \& Hogan, J. (1994). What we know about leadership: Effectiveness and personality. American Psychologists, 49, 493-504.

Hay/McBer, (2000). Research into Teacher Efectiveness: A Model of Teacher Efectiveness. Report by Hay/McBer to the Department for Education and Employment. Available at: http://www.dfee.gov.uk/teachingreforms/mcber/. 
Judge, T.A., Bono, J.E., Ilies, R., \& Gerhardt, M.W. (2002). Personality and leadership: A qualitative and quantitative review. Journal of Applied Psychology, 87(4), 765-780.

Komives, S. R., Lucas, N., \& McMahaon, T. R. (2007). Exploring leadership: For college students who want to make a diference (2nd ed.). San Francisco, CA: Jossey-Bass.

Lord, R. G., \& Shondrick, S. J. (2011). Leadership and knowledge: Symbolic, connectionist, and embodied perspectives. The Leadership Quarterly, 22(1), 207-222.

Mandell, B., \& Pherwani, S. (2003). Relationship between emotional intelligence and transformational leadership style: A gender comparison. Journal of Business and Psychology, 17(3), 387-404.

Martin, J., Knopoff, K., \& Beckman, C. (1998). An alternative to bureaucratic impersonality and emotional labor: Bounded emotionality at the Body Shop. Administrative Science Quarterly, 43, 429-469.

Maslow, A. H. (1966). Psychology of science: A reconnaissance. Retrieved from http://books.google.com

Mayer, J.D. \& Salovey, P. (1997). What is emotional intelligence? In P. Salovey \& D.J. Sluyter (Eds.), Emotional Development and Emotional Intelligence: Educational Implications: 3-31. New York: Basic Books.

Mayer, J.D., Salovey, P., \& Caruso, D. (2000). Models of emotional intelligence. In J.R. Sternburg (Ed.), Handbook of Intelligence (pp. 396-420). Cambridge, UK: Cambridge University Press.

McCrae, R.R., Costa, P.T., Jr., Lima, M.P. de., Simoes, A., Ostendorf, F., Angleitner, A.,

Marui, I., Bratko, D., Caprara, G.V., Barbaranelli, C., Chae, J.H., \& Piedmont, R.L. (1999). Age differences in personality across the adult life span: Parallels in five cultures. Developmental Psychology, 35, 466-477.

McCrae, R.R. (2000). Emotional intelligence from the perspective of the five-factor model of personality. In R. Bar-On \& J. Parker (Ed's.), The Handbook of Emotional Intelligence. San Francisco: Jossey-Bass.

Mumford, M. D., Antes, A. L., Caughron, J. J., \& Friedrich, T. L. (2008). Charismatic, ideological, and pragmatic leadership: Multi-level influences on emergence and performance. Leadership Quarterly, 19(2), 144-160.

Petrides, K.V. \& Furnham, A. (2006). The role of trait emotional intelligence in a gender specific model of organizational variables. Journal of Applied Social Psychology, 36,552-569.

Piedmont, R. (1999). Does spirituality represent the sixth factor of personality: Spiritual transcendence and the Five-Factor model? Journal of Personality, 67(6), 985-1013. 
Rockstuhl, T., Ng, K.Y., Seiler, S., Ang, S., \& Annen, H. (2009). Emotional intelligence and cultural intelligence in global leadership effective $\neg$ ness. Paper presented at the 24th Annual Con $\neg$ ference of the Society for Industrial and Orga $\neg$ nizational Psychology meeting (SIOP), New Orleans, LA.

Seltzer, J. \& Bass, B. (1990). Transformational leadership: Beyond initiation and consideration. Journal of Management, 16(4), 693-703.

Service, R. W., \& Fekula, M. J. (2008). Beyond emotional intelligence: The EQ matrix as a leadership imperative. Business Renaissance Quarterly, 3(2), 23-58.

Sosik, J., \& Megerian, J. (1999). Understanding leader emotional intelligence and performance. spirtituality and organizational performance. New York: M.E. Sharpe.

Weschler, D. (1958). The Measurement and Appraisal of Adult Intelligence (4th ed.). Baltimore: Williams \& Wilkins.

Zaccaro, S. J., Foti, R. J., \& Kenny, D. A. (1991). Self monitoring and trait-based variance in leadership: An analysis of leadership flexibility across multiple group situations. Journal of Applied Psychology, 76, 308-315. 